\title{
ARTIGO
}

\section{GERENCIANDO O ESTIGMA DO PROFESSOR CONTRATADO: UMA ANÁLISE DE DISCURSO CRÍTICA}

\author{
Cristina Spolidoro Freund" \\ Colégio Pedro II, Pontifícia Universidade Católica do Rio de Janeiro (PUC-Rio), Rio de Janeiro - RJ, Brasil \\ Liana de Andrade Biar** \\ Pontifícia Universidade Católica do Rio de Janeiro (PUC-Rio), Rio de Janeiro - RJ, Brasil
}

RESUMO: $\mathrm{O}$ artigo analisa o trabalho exercido por professores contratados em Instituições Federais de Ensino (IFEs) a partir de uma perspectiva discursiva. Assume-se que diferenças contratuais e de direitos, que precarizam relações de trabalho de professores contratados, são retroalimentadas no campo simbólico por escolhas lexicais - "efetivos" e "contratados" - que acirram a polarização entre essas categorias docentes. Em empreitada interdisciplinar, conjugando estudos sobre trabalho docente com o arcabouço teórico-metodológico da Análise de Discurso Crítica, amostra de corpus constituído por 18 autoavaliações escritas por professoras contratadas em situações reais de comunicação com a instituição foi analisada com os objetivos de identificar: marcas linguísticodiscursivas usadas em sua representação e de seu trabalho; estratégias de manejo do potencial estigmatizante, à luz de Goffman, da situação de contrato; e efeitos de sentido que ajudam a (des)construir a polarização entre professores efetivos e contratados.

Palavras-chave: Análise de Discurso Crítica. Estigma. Professores contratados.

\section{MANAGING THE HIRED TEACHER'S STIGMA: A CRITICAL DISCOURSE ANALYSIS}

ABSTRACT: The article analyzes the hired teachers labor in Federal Institutions of Education from a discursive perspective. It is assumed that different contractual and rights, which make working relationships of hired teachers quite precarious, are feed backed by the symbolic field of lexical choices - "effective" and "hired" - which reinforce the

"Doutoranda em Educação pela Pontifícia Universidade Católica do Rio de Janeiro (PUC-Rio). Mestra em Educação pela PUC-Rio. Professora do Departamento do Primeiro Segmento do Colégio Pedro II. Participa do Grupo de Estudo Formação de Professores, Currículo e Cotidiano Escolar/GEFOCC, da PUC-Rio. E-mail: csfreund@gmail.com.

"Doutora em Letras pela Pontifícia Universidade Católica do Rio de Janeiro (PUC-Rio). Professora adjunta da graduação e Programa de Pós-Graduação em Estudos da Linguagem da PUC-Rio. Coordenadora do grupo de pesquisa Narrativa e Interação Social, da PUC-Rio. E-mail: lianabiar@gmail.com 
polarization between those teachers classes. A Corpus sample (consisting of 18 self-assessments written by hired teachers in real communication situations with the institution) was analyzed within an interdisciplinary endeavor, combining studies of teaching work with the theoretical and methodological framework of Critical Discourse Analysis. The main objective was to identify (1) their linguistic-discursive marks used in their self-representation and work; (2) the management strategies of the contract situation stigmatizing potential; and (3) the effects that help to deconstruct the polarization between effective and substitute teachers.

Keywords: Critical Discourse Analysis. Stigma. Substitute teachers.

\section{INTRODUCุÃO}

O presente artigo busca lançar luz sobre uma atividade social sobre a qual poucas pesquisas foram realizadas: o trabalho exercido por professores temporariamente contratados em Instituições Federais de Ensino (IFEs) brasileiras. Em tais instituições, os professores podem trabalhar a partir de duas modalidades de contratação diferentes: no vocabulário nativo, "efetivos" e "contratados". Entre os professores "efetivos" da rede federal de ensino estão os que prestam concurso público para provimento de cargo de docente, pertencentes ao corpo de servidores federais do Executivo, gozando de estabilidade e demais direitos regidos por legislação própria ao corpo executivo do Governo Federal. Entre os professores "contratados", que podem ser temporários ou substitutos, estão aqueles que passam por processo seletivo simplificado, com contrato por período máximo de dois anos, regido conforme a Consolidação das Leis Trabalhistas.

Há, entre "efetivos" e "contratados", diferenças contratuais, de direitos, de possibilidades de carreira, de funções e de salários que precarizam as relações de trabalho do segundo grupo em relação ao primeiro. Além disso, notamos que essa diferenciação formal é retroalimentada em um plano simbólico, pelas duas escolhas lexicais que nomeiam diferentemente ambas as categorias. Muitas vezes presente na fala de alunos, funcionários e demais professores, a categorização nominal "contratado" é plena de significações com potencial estigmatizante (GOFFMAN, 1988), fazendo emergir semas de inexperiência, vulnerabilidade contratual, exclusão do corpo docente principal, entre outros. Nossa proposta neste artigo, de maneira geral, é justamente nos debruçar sobre uma das formas discursivas que povoam a prática docente de professores contratados, na tentativa de identificar as marcas linguístico-discursivas e os prováveis efeitos de sentido que ajudam a (des)construir a polarização entre professores efetivos e contratados. 
Mais especificamente, adentra uma dessas instituições em que tal polarização se faz presente, aqui denominada Colégio X. ${ }^{1} \mathrm{~A}$ instituição em tela comporta diversas modalidades de ensino (toda a Educação Básica, em várias modalidades, e algumas ofertas de mestrados, extensão e especialização profissionais) e vários campi. Por limitações próprias da atividade de pesquisa, delimitamos a situação de contratados em um campus de Ensino Fundamental (do $1^{\circ}$ ao $5^{\circ}$ ano) situado na Zona Norte do Rio de Janeiro. Em final de 2014, essa unidade escolar contava com cerca de trinta professores contratados, o que correspondia a $24,5 \%$ de total de docentes da unidade. Nessa instituição, os docentes contratados são submetidos a uma avaliação, ao final do primeiro ano letivo de contrato, que define a renovação ou rescisão dos contratos. Uma de suas etapas é uma autoavaliação escrita dos docentes sobre o seu trabalho. Tais autoavaliações constituem o corpus de análise de nossa pesquisa.

Em empreitada interdisciplinar, que conjuga os estudos sobre trabalho docente (TARDIF; LESSARD, 2005) com estudos provenientes da Análise de Discurso Crítica (ADC) (FAIRCLOUGH, 2012; RESENDE; RAMALHO, 2006, 2011), analisaremos, a partir das categorias analíticas que emergem de uma "apreciação crítica explicatória" (BHASKAR, 1986² apud FAIRCLOUGH, 2012, p. 311), um conjunto selecionado de 18 autoavaliações de professoras contratadas, aqui reduzidos a três exemplos prototípicos das estratégias discursivas de autorrepresentação empregadas.

Para cumprir seus objetivos, este artigo se estrutura da seguinte maneira: em primeiro momento, apresentamos a prática social sob escrutínio (o trabalho de docentes contratados em uma IFE). Fazendo uso do método da "apreciação crítica explicatória", buscamos identificar os problemas emergentes dessa prática social, bem como seu aspecto semiótico. Em seguida, empreendemos análise discursiva de três textos para, finalmente, apresentarmos algumas de nossas considerações sobre os resultados da pesquisa.

\section{IDENTIFICANDO O PROBLEMA SOCIAL QUE APRESENTA UM ASPECTO SEMIÓTICO}

Nascida da Linguística Crítica anglo-saxã, Norman Fairclough (2012, p. 307) enquadra a Análise do Discurso Crítica como "perspectiva teórica" sobre a semiose que possibilita uma análise linguística apoiada em reflexões sobre o processo social. Fairclough (2012, p. 308) argumenta que a semiose "inclui todas as formas de construção de sentidos" da vida social, constituída de diversas práticas: "vemos a vida social como uma rede interconectada de práticas sociais 
de diversos tipos (econômicas, políticas, culturais, entre outras), todas com elemento semiótico" (FAIRCLOUGH, 2012, p. 308).

As práticas sociais englobam as "perspectivas de estrutura e de ação", já que uma prática apresenta uma "maneira relativamente permanente de agir em sociedade", e também "um domínio de ação social e interação que reproduz estruturas, podendo transformá-las" (FAIRCLOUGH, 2012, p. 308). Na perspectiva do realismo crítico abraçada por Fairclough, todos os momentos da prática social são permeados e mediados pela semiose, e é objetivo geral do analista observar as "relações dialéticas entre semioses (inclusive a língua) e outros elementos da prática social" (FAIRCLOUGH, 2012, p. 309). Ao utilizar a "apreciação crítica explicatória" de Bhaskar $\left(1986^{3}\right.$ apud FAIRCLOUGH, 2012, p. 311-312), a ADC sempre parte de um problema social concreto, sendo, portanto, "uma forma de ciência social crítica", com "objetivos emancipatórios e focaliza nos chamados “perdedores”" (FAIRCLOUGH, 2012, p. 312).

Como já mencionamos, a ADC pretende ser uma teoria social crítica, "projetada para mostrar problemas enfrentados pelas pessoas em razão de formas particulares de vida social" (FAIRCLOUGH, 2012, p. 312). Nessa visada, as primeiras perguntas a serem feitas pelo(a) pesquisador(a) seriam: "Qual o problema?" e "Para quem este problema é grave?”. Neste estudo, conforme alinhavado na introdução, pretendemos usar essa poderosa ferramenta de análise para lançar luz sobre o trabalho docente, especificamente o problema da polarização entre "efetivos" e "contratados" nas Instituições Federais de Ensino.

A esse respeito, pode-se dizer que a questão do trabalho exercido por professores contratados se insere em uma ordem social mais ampla. No Brasil, desde 1993, é possível a contratação de professores em regimes diferentes no serviço público (professores efetivos, que prestam concurso público; e contratados regidos pela Consolidação de Leis Trabalhistas, por período de trabalho máximo de dois anos). A partir da divulgação e da concretização do Plano Diretor da Reforma do Aparelho do Estado (BRASIL, 1995), essa diferença se acentuou. O Plano defendia a contratação de parte dos servidores federais como celetistas, dentro de projeto inspirado nas reformas mundiais realizadas em outros países, e defendia a implementação da "nova gestão pública", com bases "modernas e racionais" (BRASIL, 1995, p. 6) de gerencialismo do Aparelho do Estado no Brasil. Em 1995, à mesma época da divulgação do Plano Diretor, a Organização para Cooperação do Desenvolvimento Econômico (OCDE) lançou o relatório "Governance in Transition: Public Management Reforms in OECD Countries"" (apud BALL, 2001). Esse pacote de reformas, 
com incentivos e objetivos para os países, pretendia mudar a atuação do Estado, implementando o gerencialismo, a responsabilização e o controle dos resultados, e não dos processos, como era feito na forma existente, até então, de administração pública do Estado Burocrático.

Como apontado por Fairclough (2012, p. 315), "língua e semiose têm uma considerável importância na reestruturação e reescalonamento do capitalismo". As mudanças introduzidas nos discursos que circulam na sociedade mudam a forma de representarmos o mundo, e pelo discurso podemos também apreender os novos significados identificacionais - isto é, como as identidades são negociadas pelo discurso - e acionais - significados pelos quais os discursos tendem a representar nossa forma de agir em interação social. Dessa forma, pela agenda da nova gestão pública a serviço do neoliberalismo, discursos representando o Estado como uma estrutura "pesada", "ultrapassada", "burocrática", seus servidores como "preguiçosos", entre outros, vão se legitimando na sociedade e dando margem a mudanças nas práticas sociais.

Se, na década de 1980, era inconcebível haver professores atuando em IFE que não fossem servidores públicos efetivos, devendo o governo federal prover os cargos necessários para seu bom funcionamento, inclusive realizando concursos públicos, na década de 1990 se iniciou outra etapa nas práticas desse campo. Os discursos presentes no documento do Plano Diretor da Reforma do Aparelho do Estado introduzem novos sentidos para o trabalho do servidor:

É preciso, agora, dar um salto adiante, no sentido de uma administração pública que chamaria de "gerencial", baseada em conceitos atuais de administração e eficiência, voltada para o controle dos resultados e descentralizada para poder chegar ao cidadão, que, numa sociedade democrática, é quem dá legitimidade às instituições e que, portanto, se torna "cliente privilegiado" dos serviços prestados pelo Estado. (BRASIL, 1995, p. 7)

Como um dos pilares da Reforma do Aparelho do Estado, Bresser Pereira e sua equipe propõem, no documento, o conceito de publicização:

[...] a descentralização para o setor público não-estatal da execução de serviços que não envolvem o exercício do poder de Estado, mas devem ser subsidiados pelo Estado, como é o caso dos serviços de educação, saúde, cultura e pesquisa científica. (BRASIL, 1995, p. 12-13)

Não cabe nos limites do presente trabalho um detalhamento dessa reforma. Destacamos, no entanto, que seu discurso foi, paulatinamente, incorporado aos discursos sociais. A partir daí, legitimou-se a ideia de que a educação pode ser publicizada - ou seja, 
o Governo a "subsidia", exercendo o papel de regulador, controlador, gerente à distância. A IFE em foco em nossa pesquisa, por exemplo, tornou-se uma autarquia, com "liberdade" administrativa dentro dos preceitos legais. Entretanto, os subsídios governamentais para esse tipo de instituição não são suficientes, e essas instituições se utilizam do recurso de contratação de professores por contrato de trabalho temporário para suprir a demanda de docentes. Dessa forma, justificada, em princípio, como forma de suprir professores em licenças para estudo ou médicas, cargos de alta gestão, entre outros, no caso de professores contratados substitutos, e para suprir a expansão da rede, no caso dos contratados temporários, essa contratação de professores nas IFEs vem crescendo no país. $\mathrm{Na}$ IFE em que ocorreu a pesquisa, chega a ultrapassar os $20 \%$ permitidos por lei em alguns dos seus campi. Isso ocorre também porque os concursos públicos autorizados e realizados não conseguem suprir a demanda por professores, tanto devido a situações como aposentadoria, exonerações, licenças pessoais, como também pela expansão da rede e da oferta educacional.

Afinal, em que tais considerações contribuem para a definição do problema social em tela? Respondemos a essa pergunta a partir de alguns desdobramentos da contratação de professores. Em primeiro lugar, argumentamos que essa forma de contratação se caracteriza como estratégia de flexibilização do trabalho docente, flexibilização que diminui o custo-professor para o Estado e que aprofunda um

[...] mercado de trabalho diversificado e fragmentado, composto por poucos trabalhadores centrais, estáveis, qualificados e com melhores remunerações e um número cada vez maior de docentes periféricos, temporários, em mutação e facilmente substituíveis. (MANCEBO; FRANCO, 2003, p. $193^{5}$ apud MANCEBO, 2007, p. 407-408)

Essa situação é apontada também por Faria (2010, p. 22) como representante da "flexibilidade funcional", ou seja, como formas de trabalho sem contratação ou com contrato temporário, com menores garantias, as quais geram insegurança.

Além disso, o contrato de trabalho é um problema não apenas para o professor contratado, que se encontra em situação funcional com menores garantias, menores possibilidades de escolha, é também para a instituição, já que esta precisa renovar periodicamente seu corpo de professores, recebê-los, introduzi-los na cultura institucional, nos aspectos estruturais da atividade docente (TARDIF; LESSARD, 2005), para que os alunos não sejam penalizados com a troca constante.

Sobre os aspectos simbólicos (problemas linguísticos com impacto na vida social) dessa questão da própria existência de professores contratados, um primeiro aspecto do problema 
é a existência do exercício de atividade social por professores em condições diferenciadas em relação a outros docentes: situação de estar contratado exercendo a docência versus ser efetivo. Aí se coloca também uma questão de semiose: a diferença de denominação entre professor contratado/efetivo representa diferença de estilo, para os próprios professores, quanto a suas "maneiras de ser, identidades" (FAIRCLOUGH, 2012, p. 310). Como afirmam Resende e Ramalho (2011, p. 142): “a categorização influencia os modos como as pessoas agem e pensam sobre uma dada situação, por isso a preocupação com a questão da classificação é essencial”.

No plano interacional, tem-se muitas vezes configurado um "estigma" (GOFFMAN, 1988). Em termos goffmanianos, estigma é uma marca de diferença que se torna relevante em encontros interacionais. Tais como marcas corpóreas, comportamentais ou de origem, argumentamos que "estar contratado" é marcado em relação a ser efetivo, e essa marca se faz presente nas múltiplas interações entre alunos e professores, professores e professores, direção/coordenação e professores. Tal marcação não está isenta de conotações negativas que identificam contratados como professores menos experientes e mais vulneráveis e relações de poder e assimetrias institucionais, construídas e reproduzidas discursivamente.

Podemos agora especificar o problema específico sobre o qual nos debruçamos em nosso trabalho nos seguintes termos: como os professores contratados, com menor poder dentro da instituição, representam-se e às suas práticas profissionais como professores contratados frente aos interesses, demandas e projetos institucionais? De que maneira suas estratégias discursivas reforçam ou manejam o estigma institucional da contratação?

No presente trabalho, analisaremos essas questões, como anunciamos, conforme construídas em textos de autoavaliação escritos por professores contratados de uma instituição federal. Esses textos, escritos pelos docentes sempre ao final do ano letivo, compõem, no caso dessa instituição, o processo de avaliação com fim de renovação ou rescisão do contrato de trabalho.

\section{IDENTIFICANDO OBSTÁCULOS PARA A RESOLUC̣ÃO DO PROBLEMA}

No enquadre de análise de práticas sociais proposto por Fairclough, após identificar-se problema social foco o da pesquisa, bem como sua contraparte semiótica, é preciso refletir sobre os obstáculos para resolução. Segundo o autor, "os obstáculos são, também, parte de um problema de dominação ou de influência nas formas de interação, 
do uso da linguagem" (FAIRCLOUGH, 2012, p. 313). Interação, para Fairclough, tem sentido amplo - ocorre tanto em contextos de interação sincrônica e face a face quanto em artigo de jornal, por exemplo, em que a comunicação é mediada e assíncrona. De acordo com Bakhtin (2000), todo enunciado é um elo na cadeia de muitos outros enunciados, relacionados dialogicamente. As autoavaliações escritas pelas professoras, que analisaremos, a seguir, são exemplares desta segunda forma de interação, que tem origem em enunciador localizado sócio-historicamente e dirigida a um interlocutor também posicionado no tempo-espaço, passível de atitudes responsivas ativas, e, portanto, de uma análise dos seus significados acionais (gêneros discursivos), representacionais (discursos recrutados) e identificacionais (estilos de escrita), com vistas a iluminar os mecanismos que naturalizam certas relações de poder.

As seções seguintes, dedicadas à análise de dados, focalizam três desses textos. Escritos por professoras substitutas ao final de 2014, para compor sua avaliação como contratadas, os textos respondiam à seguinte proposta: "Relate sua experiência como Professor Contratado ${ }^{6}$ do Colégio $\mathrm{X}$ avaliando seu desempenho e especificando as dificuldades que encontrou, bem como os pontos positivos de sua experiência no Colégio".

Acerca dos aspectos interacionais presentes na autovaliação, pode-se destacar que ela pode ser entendida com base na noção de encontro misto (GOFFMAN, 1988). Para Goffman, o encontro interacional (mesmo que assíncrono) entre uma identidade estigmatizada - em nosso contexto, o professor contratado, lado mais fraco na balança de poder - e uma hegemônica - os profissionais de educação responsáveis por manter ou rescindir o contrato de trabalho, o lado mais forte - gera uma série de estratégias discursivas de manejo da relação de poder de forma a anular ou, ao menos, amenizar os conflitos potenciais causados pela assimetria entre os participantes. As duas primeiras respostas aqui analisadas foram escritas por professoras que atuavam no Núcleo de Atendimento às Pessoas com Necessidades Específicas (NAPNE) da instituição. Já a terceira autoavaliação foi escrita por uma professora de $5^{\circ}$ ano do Ensino Fundamental da mesma instituição. Veremos, no entanto, que a forma como respondem suas autoavaliações e se posicionam como contratadas é bastante diferente entre si. Pretendemos ancorar essas diferenças no exame dos recursos léxico-gramaticais empregados para manejar o estigma, contornar as delicadezas interacionais que envolvem uma autoavaliação por parte de alguém em contrato precário.

A esse respeito, como defendem Resende e Ramalho (2011, p. 108), uma das formas pelas quais podemos depreender o obstáculo 
a ser superado acerca do problema social em foco é pela análise de textos, que concretizam a prática social:

A análise detalhada e intensiva de textos como elementos de processos sociais
é, nos termos de Chouliaraki \& Fairclough (1999), um processo complexo que
engloba duas partes: a compreensão e a explanação. Um texto pode ser compreendido
de diferentes maneiras. [...] Parte da análise de textos é, portanto, análise de
compreensões, que envolvem descrições e interpretações. A outra parte da análise
é a explanação, que se situa na interface entre conceitos e material empírico. Trata-se de
um processo no qual propriedades de textos particulares são "redescritas" com
base em um arcabouço particular, com a finalidade de "mostrar como o momento
discursivo trabalha na prática social, do ponto de vista de seus efeitos em lutas
hegemônicas e relações de dominação. (CHOULIARAKI; FAIRCLOUGH,
1999, " p. 67 apud RESENDE; RAMALHO, 2011, p. 108)

Para realizar o exame do texto, nos utilizaremos de categorias analíticas típicas da Análise de Discurso Crítica, que são

[...] formas e significados textuais associados a maneiras particulares de representar, de (inter)agir e de identificar-(se) em práticas sociais situadas. Por meio delas, podemos analisar o texto buscando mapear conexões entre o discursivo e o não discursivo, tendo em vista seus efeitos sociais. (RESENDE; RAMALHO, 2011, p. 111-112).

Assim sendo, selecionamos categorias analiticas que nos permitem apreender as semelhanças e diferenças entre as representações das professoras e seus modos de lidar com as questões de poder presentes na sua atuação como docentes contratadas. As categorias analíticas selecionadas para este fim são as seguintes: estrutura genérica, transitividade, interdiscursividade, identificação e avaliação. Na próxima seção, definiremos brevemente cada uma dessas categorias, procedendo na sequência a análise nos excertos selecionados.

\section{As estratégias discursivas da professora Gabriela}

Conforme lembram Resende e Ramalho (2011), a estrutura de um texto está associada ao gênero textual, e esse a um significado acional. Cada gênero, "como modo de interação", implica uma atividade específica, "ligada a práticas particulares" (RESENDE; RAMALHO, 2011, p. 126). Os gêneros se relacionam com o que as pessoas fazem e com suas respectivas finalidades (RESENDE; RAMALHO, 2011, p. 126). Sobre as finalidades, ou propósitos, esses se concretizam nos textos em movimentos retóricos: "movimentos discursivos, com um propósito particular pontual, que servem aos propósitos globais de gênero e que se distribuem de maneira não sequencial e não obrigatória" (RESENDE; RAMALHO, 2011, p. 127). 
Fairclough afirma que gêneros podem variar de acordo com o seu nível de abstração. Os pré-gêneros seriam categorias mais abstratas, utilizadas na "composição de outros tipos de texto" (FAIRCLHOUGH, $2003^{8}$ apud RESENDE; RAMALHO, 2006, p. 63). A narrativa é um pré-gênero presente nas autoavaliações, como se verá no texto da professora Gabriela, reproduzido a seguir.
A minha experiência como professora contratada do colégio $\mathrm{X}$ tem provocado em mim um grande crescimento profissional. Me sinto muito feliz em realizar meu trabalho que faço com afinco e dedicação.
Dessa forma, trabalhar nessa renomada instituição de ensino constitui, a meu ver, motivo de honra e prazer. Avalio meu desempenho como professora substituta e professora mediadora (bidocente) como experiência positiva, pois me realizo profissionalmente enquanto desenvolvo minhas tarefas pedagógicas.
Além do mais, tenho tido a oportunidade de fazer cursos nesta área e de me capacitar para melhor exercer minha função.
Também tenho recebido a orientação e supervisão do NAPNE, que tem realizado um trabalho gabaritado nesta área de educação especial, que tem como principal objetivo promover a inclusão com efetividade.
Enfim, me sinto muito feliz em fazer parte da equipe de contratados. (Texto 1 - autoavaliação da professora Gabriela) ${ }^{9}$

A professora redige seu relato de avaliação predominantemente no presente durativo, recurso útil para se apresentarem esforços e sentimentos como permanentes e em curso:

(1) ${ }^{10}$ A minha experiência como professora contratada do colégio X tem provocado em mim um grande crescimento profissional.

(2) Além do mais, tenho tido a oportunidade de fazer cursos nesta área e de me capacitar para melhor exercer minha função.

(3) Também tenho recebido a orientação e supervisão do NAPNE, que tem realizado um trabalho gabaritado.

Por outro lado, Resende e Ramalho (2011, p. 143) sinalizam que a grande concentração de verbos no presente é um recurso que opera ideologicamente na medida em que faz omitir os processos, contribuindo para estratégias de reificação daqueles. No caso de Gabriela, o relato parece afirmar que são honra e prazer trabalhar no colégio - seu passado como professora fica obscurecido pela presente atuação como docente contratada. Pressupostos em seu discurso são as crenças que privilegiam a qualidade e a tradição da instituição, com as quais a professora se alinha.

Quanto à transitividade, Resende e Ramalho (2011, p. 140) afirmam que essa categoria permite analisar "como o/a locutor/a representa aspectos do mundo", e as escolhas gramaticais no sistema 
da transitividade "permitem analisar quem faz o quê, a quem e em que circunstâncias". A transitividade está relacionada ao significado representacional do discurso. Para Halliday (2004, p. $172^{11}$ apud RESENDE; RAMALHO, 2011, p. 139-140), por exemplo, a categoria descreve processos "materiais, pelos quais se representam ações, eventos; os mentais, que representam percepções, emoções; e os relacionais, que identificam, caracterizam os participantes".

A esse respeito, nota-se que a professora Gabriela utiliza a voz ativa em poucos momentos, e sempre mediante uso de verbos que indicam processos mentais, ligados à avaliação, que analisaremos à frente:

(4) Me sinto muito feliz em realizar meu trabalho que faço com afinco e dedicação.

(5) Enfim, me sinto muito feliz em fazer parte da equipe de contratados.

(6) Avalio meu desempenho como experiência positiva.

Em outros momentos, os processos materiais parecem incidir sobre ela, ou seja, outros agentes são mais ativos na situação:

(7) Além do mais, tenho tido a oportunidade de fazer cursos nesta área e de me capacitar para melhor exercer minha função.

(8) Também tenho recebido a orientação e supervisão do NAPNE, que tem realizado um trabalho gabaritado nesta área de educação especial, que tem como principal objetivo promover a inclusão com efetividade.

Nos excertos apresentados, os agentes da prática social foram deslocados da professora para a experiência na escola (1), ou para a oportunidade (7) ou para o NAPNE (8). Esse deslocamento da ação para entidades impersonalizadas, como experiência e oportunidade (THOMPSON, 1995) ou para outro grupo de atores sociais, o NAPNE, aliado a verbos que representam processos mentais, têm como efeito uma subalternização da professora em relação ao colégio, à instituição. Gabriela se sente privilegiada por aprender tanto durante sua experiência profissional e parece expressar que mais "sofre" a ação da escola sobre ela do que vice-versa, o que tem efeito sobre a categoria identificacional - apresenta-se como "professoraquase-aluna". Essa forma de se construir pode funcionar como poderoso recurso estratégico no que se refere à prática discursiva da autoavaliação: ao elogiar a instituição e apresentar-se como aprendiz, Gabriela está manejando a sua posição de contratada e mobilizando supostas expectativas de assimetria em relação a ela.

Acerca da identificação relacional, Resende e Ramalho explicam que essa categoria

[...] diz respeito à identificação de atores sociais em textos em termos das relações pessoais, de parentesco ou de trabalho que têm entre si. Esse tipo de identificação 
é 'relacional' no sentido de que depende das relações sociais estabelecidas e das posições sociais que os atores sociais ocupam. (RESENDE, $2009^{12}$ apud RESENDE; RAMALHO, 2011, p. 131)

A identificação - o significado identificacional - relacionase ao estilo, a forma pela qual o locutor identifica-se aos demais atores no discurso. A professora Gabriela identifica a instituição ("renomada instituição de ensino") a si mesma na relação com a instituição como professora "contratada" (1), pertencente "à equipe de contratados" (5). Outra instância mencionada é o NAPNE, órgão que a orienta, supervisiona e realiza "trabalho gabaritado" na área de educação especial (8). A identificação por nomeação dá ainda mais força à competência da outra equipe de atores sociais, na qual a professora exerce a função de mediadora, precisando, porém, de supervisão e orientação. A identificação da professora como a que é orientada constrói sua subalternidade em relação à renomada instituição reforçando a naturalização da relação de poder. Por outro lado, pode ser a forma pela qual a professora está jogando o jogo, de forma estratégica (FAIRCLOUGH, 2012, p. 316), para conquistar a complacência de quem detém o poder de avaliá-la.

A avaliação - outra categoria analítica - nos indica aspectos que estão em consonância com as demais. Segundo Resende e Ramalho (2011, p. 119),

[...] avaliações são significados identificacionais que podem ser materializados em traços textuais como afirmações avaliativas, afirmações com modalidades deodônticas, avaliações afetivas e presunções valorativas. A avaliação é, em princípio, uma categoria identificacional, moldada por estilos.

Afirmação avaliativa é uma avaliação explícita (por exemplo: “Adoro! Que bom, etc.”) ou com o "elemento avaliativo" pressuposto (RESENDE; RAMALHO, 2011, p. 119). Uma afirmação com modalidade deodôntica indica avaliações em termos de obrigações e necessidades. Avaliações afetivas referem-se aos processos mentais afetivos. Essas todas são avaliações explícitas. Ocorre frequentemente também, nos textos, um tipo de avaliação implícita, a presunção valorativa, em que algumas palavras denotam a avaliação (RESENDE; RAMALHO, 2011, p. 120).

A professora Gabriela registra várias avaliações explícitas. Por exemplo, é explícita em sua avaliação abaixo:

(9) Dessa forma, trabalhar nessa renomada instituição de ensino constitui, a meu ver, motivo de honra e prazer. Avalio meu desempenho como professora substituta e professora (bidocente) como experiência positiva, pois me realizo profissionalmente enquanto desenvolvo minhas tarefas pedagógicas. 
No excerto 9, a professora utiliza-se de qualificadores e expressões positivas para categorizar a instituição e seu trabalho. Gabriela lança mão também de avaliação deodôntica no excerto 7 (a oportunidade de fazer cursos e se capacitar, pois é necessidade para melhor atuação). Embora não explicite a relação da instituição com os cursos, fica subentendido que, de alguma forma, foram oportunizados pelo colégio. Outra avaliação aparece como presunção valorativa, conforme o excerto 8 - “tem recebido a 'orientação' e 'supervisão' do NAPNE”, com seu trabalho "gabaritado". Embora a avaliação seja implícita, a professora parece estar satisfeita com esse apoio a seu trabalho.

Finalmente, lançaremos foco afora na categoria analítica interdiscursividade. Conforme Resende e Ramalho (2011, p. 142), essa categoria nos permite investigar "discursos articulados em textos e suas conexões com lutas hegemônicas mais amplas". Pela observação e análise do discurso e da seleção lexical, pode-se apreender a presença de diversos projetos e campos sociais.

Quando a professora registra que é "motivo de 'honra' e 'prazer" trabalhar "nesta renomada instituição" (9), traz pressuposta a ideia de que há instituições de ensino com maior ou menor "nome", o que se pode ligar a status, reconhecimento social, e, portanto, que há diferenças entre as diferentes instituições. Também há uma pequena influência de discurso pedagógico relacionado à área da educação especial ("promover a inclusão com efetividade") que demonstra a concepção de Educação Especial da escola com a qual a professora se alinha, dadas as diferentes disputas sobre as possíveis concepções da área. Outro discurso que se faz presente é o do campo da teoria do Capital Humano. Quando a professora fala em fazer cursos e se "capacitar para melhor exercer sua função" (7), traz para o campo pedagógico termos e crenças do campo econômico. Como advoga Schultz (1961, p. 2), "ao investirem em si mesmas, as pessoas podem aumentar o leque de opções disponíveis para si", aumentando seu patrimônio. Dessa forma, em seu texto de autoavaliação, a professora ratifica e se alinha com a ideia de que uma boa profissional precisa investir em sua própria capacitação, fato com o qual os professores de vários países também se alinham, conforme constatam Tardif e Lessard (2005, p. 137).

Por meio da análise das categorias destacadas, é possível perceber que as estratégias utilizadas pela professora para "equilibrar" a balança do poder, em sua autoavaliação, reforçam e naturalizam as relações de poder, uma vez que a professora centra a ação na escola e seus órgãos, colocando-se como aquela que se beneficia da experiência, falando muito pouco dos ganhos que a instituição tem com sua atuação profissional. Como já se disse, na avaliação construída 
por Gabriela, a instituição de renome faz com que a professora se desenvolva profissionalmente, em contato com seus gabaritados membros, com quem ela se relaciona como aprendiz-professora e em processo de capacitação. Como parte de suas estratégias discursivas, destacamos também que a professora optou por omitir as "dificuldades apresentadas", presentes na proposta da tarefa ("Relate sua experiência como Professor Contratado do Colégio X, avaliando seu desempenho e especificando as dificuldades que encontrou, bem como os pontos positivos de sua experiência no Colégio").

Antes de tecermos conclusões mais gerais sobre essa análise, passaremos à análise do Texto 2 .

\section{As estratégias da professora Ana}

Diferentemente da professora Gabriela, a professora Ana optou, na redação de seu texto, por modalidade retórica com marcas narrativas. $\mathrm{O}$ uso de enunciado que sobrepõe ações verbais organizadas cronologicamente, característico da narrativa, contrasta sua percepção quanto à atuação em momentos diferentes com relatos sobre sua trajetória da escola.

Quando fiz a prova do concurso para o Colégio X estava passando por um momento de frustração profissional, pensando em desistir do magistério devido a algumas experiências desagradáveis que tinha presenciado. Que bom que eu não desisti! Pois ver e participar da educação que eu acredito é fantástico.

Apesar de estar aqui há pouco tempo (+- 3 meses) pude participar de ações que fazem os alunos pensarem, se expressarem e viverem de forma plena aquele conhecimento.

Fui agraciada com a mediação de dois alunos que vieram no momento certo (concluí a Pós-Graduação em Psicopedagogia Institucional e Educação Especial) e que me trazem desafios diários e estímulo para continuar me aprimorando (estou fazendo o curso de Mediação Escolar, oferecido pelo Colégio X). A educação especial sempre me despertou atenção e a cada dia levanta mais questionamentos que me levam à pesquisa desse assunto tão amplo e ao mesmo tempo tão específico. Acredito que o fator imprevisibilidade é o que torna, para mim, esta vertente da educação tão admirável e surpreendente.

Ao longo desses três meses surgiram dúvidas e dificuldades, mas estas foram sanadas com a ajuda da equipe (NAPNE, Direção, SESOP, Coordenação de Turno, docentes...) e que resultou na solução total e/ou parcial daquela problemática.

Espero aprender a cada dia com o Colégio X e continuar crescendo pessoalmente e profissionalmente. (Texto 2 - autoavaliação da professora Ana) ${ }^{13}$

Os excertos de 10 a 12 apresentam marcadores temporais que estabelecem contraste entre dois ou mais episódios cronologicamente 
organizados. Esse tipo de relato narrativo permite à professora evidenciar sua mudança de "estado" desde sua entrada na instituição:

(10) Quando fiz a prova do concurso para o Colégio X, estava passando por um momento de frustração profissional, pensando em desistir do magistério devido a algumas experiências desagradáveis que tinha presenciado.

(11) Apesar de estar aqui há pouco tempo (+- 3 meses), pude participar de ações que fazem os alunos pensarem, se expressarem e viverem de forma plena aquele conhecimento.

(12) Ao longo desses três meses surgiram dúvidas e dificuldades, mas estas foram sanadas com a ajuda da equipe (NAPNE, Direção, SESOP, ${ }^{14}$ Coordenação de Turno, docentes...) e que resultou na solução total e/ou parcial daquela problemática.

Além disso, nota-se também mistificação de sua experiência na escola, a partir do uso de uma "virada narrativa tipicamente literária" (RESENDE; RAMALHO, 2011, p. 128):

(13) Fui agraciada com a mediação de dois alunos que vieram no momento certo (concluí a Pós-Graduação em Psicopedagogia Institucional e Educação Especial) e que me trazem desafios diários e estímulo para continuar me aprimorando (estou fazendo o curso de Mediação Escolar, oferecido pelo Colégio X).

Essa estrutura retórica permite que a professora apresente a sua experiência no colégio de forma inusitada, em espécie de relato de redenção: a escola foi a solução de seus problemas frente a sua decepção com o trabalho docente. O efeito disso é uma subversão dos propósitos da avaliação: a professora passa a avaliar a utilidade da escola para a realização de seus projetos pessoais. É a instituição que está a serviço de sua vida e expectativas; a professora é "agraciada". A escola serviu para redimi-la de situação desagradável, contribuiu para sua persistência na profissão. Os alunos especiais "vieram no momento certo" (13) para sua vida profissional. Parece que a experiência no Colégio X foi uma "graça" - no sentido de bênção divina, inesperada, gratuitamente dada - para sua vida.

Por outro lado, considerando-se que a identidade é construída em nossas relações, inclusive a identidade profissional, esse relato também aponta uma possibilidade: a de que a professora tenha percebido outras possibilidades de estar e ser professora, diferentes de experiências negativas presenciadas. Talvez estar em outro contexto institucional, em suas palavras, o "da educação em que acredita", a auxilie na construção de outra identidade profissional e identificar fatores sociais e econômicos que interferem nesse ser professor, que não se constrói de forma isolada do contexto em que trabalha. Então, sobre a identificação relacional, a professora apresenta posicionamento 
mais ativo e menos hierarquizado que sua colega Gabriela. No excerto 13, apesar da impressão de que os alunos estão a serviço de sua "redenção" no magistério, a professora se constrói como quem se relaciona com eles de forma interativa, pois eles lhe "trazem desafios diários e estímulo para continuar [se] aprimorando". No excerto 11, a professora agiu com demais membros da instituição para dar cabo a "ações que fazem os alunos pensarem, se expressarem e viverem de forma plena aquele conhecimento" e não se colocou como subalterna, mas como uma igual na ação - ao não nomear os demais sujeitos, ofuscando-os, destacou sua própria ação. E, no excerto 13, indica que contou com a "ajuda da equipe" para sanar dificuldades e dúvidas. A professora busca, dessa forma, construir discurso em que sua identidade se mostre menos fragilizada e dependente de outros.

Resende e Ramalho citam Castells (1999, p. $23^{15}$ apud RESENDE; RAMALHO, 2006, p. 77) e três formas possíveis de construção de identidades em contextos de poder: identidade legitimadora; de resistência; e de projeto. Enquanto a primeira legitima a dominação, a segunda se constrói por atores em contexto de dominação e é um foco de resistência. Já “a identidade de projeto é construída quando atores sociais buscam redefinir sua posição na sociedade e constitui recurso para mudança social" (RESENDE; RAMALHO, 2006, p. 78). A esse respeito, vejamos o excerto 14:

(14) Que bom que eu não desisti! Pois ver e participar da educação que eu acredito é fantástico.

Nota-se que a professora legitima o projeto de educação que vivencia atualmente como seu projeto para o magistério, em detrimento de projetos identitários anteriores.

No excerto 10, a professora faz afirmação avaliação negativa explícita: "estava passando por um momento de frustração profissional, pensando em desistir do magistério devido a algumas experiências desagradáveis que tinha presenciado". Ela preferiria abrir mão da profissão a continuar compactuando com situações presenciadas. A sequência é uma avaliação positiva: "que bom que eu não desisti!" (14). A ênfase se dá no ponto de exclamação e na expressão "que bom". Ana não chega a se constituir a partir de uma identidade de resistência; ela se coloca, ao contrário, como alguém que, embora se liberte da realidade incômoda, só o faz a partir do momento em que o contexto educacional é compatível com suas representações sobre um ideal da educação: "Pois ver e participar da educação que eu acredito é fantástico” (14). 
Quanto à categoria transitividade, essa professora apresenta-se mais como agente do que como aquela que sofre as ações da instituição. Há mais verbos que indicam processos materiais ("fiz a prova", "ver e participar da educação que acredito", "pude participar de ações", "me tražem desafios", "conclui a Pós-graduação", "estou fazendo o curso de Mediação Escolar oferecido pelo Colégio"). Assim, ela se constrói mais como participante ativa da educação do que como alguém sujeito a desígnios alheios à sua vontade. E, quando tais desígnios são expressos, aparecem como algo positivo: "Fui agraciada" - como um processo mental positivo, indicador da graça recebida. O mesmo acontece em: "surgiram dúvidas e dificuldades, mas estas foram sanadas com a ajuda da equipe (NAPNE, Direção, SESOP, Coordenação de Turno, docentes...) e que resultou na solução total e/ou parcial daquela problemática" (14). A equipe a ajudou, indicando parceria (no lugar de tutoria, conforme se vê na análise do Texto 1). Apesar disso, são curiosas a opção de nomeação dos órgãos e a impessoalidade dos atores: NAPNE, Direção, etc. - a longa lista parece flutuar à sua volta, pronta e preparada para lhe ajudar e redimir sempre que necessária.

Quanto à interdiscursividade, a professora também traz discurso sobre a Educação Especial:

(15) A educação especial sempre me despertou atenção e a cada dia levanta mais questionamentos que me levam à pesquisa desse assunto tão amplo e ao mesmo tempo tão específico. Acredito que o fator imprevisibilidade é o que torna, para mim, esta vertente da educação tão admirável e surpreendente.

Quanto à sua formação profissional, a professora faz questão de enunciar os cursos que realizou por conta própria, demonstrando preocupação em enunciar seus investimentos em si, e que aproveita o que a escola lhe oferece, bem como aplicá-los, evidente no excerto 13, pois a professora realiza atividade de mediação de dois alunos especiais.

Dentro do campo pedagógico, ao enunciar no excerto 11 que gostou de participar de ações que fizeram os alunos "pensarem, se expressarem", "viverem o conhecimento", a professora demonstra alinhamento com perspectivas sócio-construtivistas da educação, que defendem a necessidade de maiores envolvimento, participação e atividade dos alunos no processo de ensino-aprendizagem. E, finalmente, ao enfatizar a equipe, ainda que essa possa ser também estratégia discursiva para jogar o jogo interacional e manejar as diferenças (GOFFMAN, 1988), a professora evidencia acreditar que a educação não se faz sozinha e na instituição escolar ser composta por equipe que providencia ajuda mútua com modelo mais "orgânico", "abordagens colaborativas", "partilha dos saberes empíricos" (TARDIF; LESSARD, 2005, p. 108). 
Assim, podemos dizer que essa é uma professora que se constrói como alguém que age e que age com outros, em benefício dos alunos - que devem pensar, que a estimulam, que representam a escola em que age atualmente como lugar redentor para sua identidade, reforçando, porém, a ideia de que é impossível ao sujeito alterar a situação em que vive: no fim, ela precisou ser "redimida". A solução encontrada por essa professora foi corroborar o projeto do colégio com o qual se alinha. Entretanto, algumas escolhas lexicais também a identificam como "professora-ainda-aprendiz": ela fez uma prova (10) e "Esper[a] 'aprender' a cada dia com o Colégio X e continuar 'crescendo' pessoalmente e profissionalmente".

\section{As estratégias da professora Maria}

A autoavaliação escrita pela professora Maria apresenta características marcadamente diversas daquelas ressaltadas na análise dos textos de suas colegas, conforme vemos no Texto 3.

Tenho buscado sempre refletir sobre minha prática docente, atentando para a responsabilidade, capacidade, iniciativa, assiduidade e principalmente para as desafiantes e que estimulem as crianças. Afinal, entrei como regente de uma turma que já estava com uma professora há bastante tempo, no meio do ano letivo e depois de uma greve.

Entretanto, qualquer dificuldade oriunda dessa situação foi amenizada com o apoio e orientação das equipes, fator relevante em minha adaptação. Assim como a recepção da turma e compreensão dos responsáveis.

Destaco toda organização e entusiasmo dos profissionais do Colégio X como essenciais para aquilo que eu buscava encontrar: experiências no fazer da rede pública que estão distanciadas do fracasso escolar. Assim, estar aqui é a materialização do que eu imaginava para a minha trajetória como docente. (Texto 3 - autoavaliação da professora Maria)

Uma das características mais marcantes da autoavaliação de Maria é ela lançar mão de certas estratégias retóricas para trazer temas negligenciados por colegas. O texto tem início como relato no presente contínuo, que, assim como no Texto 2 apresentado neste artigo, indexicaliza ações em processo:

(16) Tenho buscado sempre refletir sobre minha prática docente, atentando para a responsabilidade, capacidade, iniciativa, assiduidade e principalmente para as necessidades de meus alunos. Tenho me esforçado para criar estratégias que sejam desafiantes e que estimulem as crianças.

Entretanto, a professora logo introduz uma oração narrativa para ressaltar elemento negativo à sua trajetória: "(17) Afinal, entrei 
como regente de uma turma que já estava com uma professora há bastante tempo, no meio do ano letivo e depois de uma greve".

O conectivo "afinal" apresenta tema ofuscado pelas duas professoras anteriores: a situação do início do contrato. A professora Ana, assim como a professora Maria, começou no meio do ano letivo, após retorno de greve docente. Entretanto, entre todas as autoavaliações que compõem esta pesquisa (dezoito), apenas a de Maria aborda o tema. Ela o faz logo após introdução em que ressalta tópicos importantes em sua atuação, apresenta a greve e o momento do contrato e retoma avaliações positivas. Há todo um cuidado para introduzir questão que talvez a professora considere ser delicada para ser abordada em autoavaliação, tarefa que, no entanto, enfrenta, construindo resistência explícita à questão do poder.

Esse movimento relaciona-se, no caso desse texto, com o seu significado representacional, ou seja, como o locutor escolhe representar o mundo e as lutas hegemônicas mais amplas. Maria trouxe para sua autoavaliação: um tema político, a greve; um tema institucional, o início dos contratos no meio do ano letivo; um tema relacional e pedagógico, como substituir professora no meio do ano letivo; e também, mais lateralmente, a discussão sobre o "fracasso escolar". Ainda que não tenha sido seu objetivo discutir esses pontos, eles acabam por destacar a agenda da professora, que se apresenta conectada a discussões e pautas sobre a profissão docente, em várias dimensões. Apresenta também, ainda que de forma incipiente, sua percepção do papel da(o) docente, conforme excerto 16: um bom professor reflete sobre sua prática, pautando a reflexão sobre uma série de itens e usa estratégias que motivem e desafiem os alunos.

Quanto à transitividade, assim como a professora Ana, Maria utiliza a voz ativa: "tenho buscado sempre refletir"; "tenho me esforçado para criar"; "entrei como regente"; "destaco"; "buscava encontrar". Desses, refletir e esforçar se referem a processos mentais. Os demais, materiais. Há apenas dois momentos em que a professora registra maior "passividade":

(18) Entretanto, qualquer dificuldade oriunda dessa situação foi ameniz̧ada com o apoio e orientação das equipes, fator relevante em minha adaptação. Assim como a recepção da turma e compreensão dos responsáveis.

(19) Assim, estar aqui é a materialização do que eu imaginava para a minha trajetória como docente.

Tal como a colega Ana, a professora menciona a ajuda das equipes, usando, entretanto, outras escolhas lexicais: no lugar de "sanadas" (12), "amenizadas" para se referir à atuação das equipes, 
dando lugar à sua própria ação, ainda que implicitamente. E menciona o papel dos responsáveis e alunos nesse processo, mostrando-se pessoa que consegue interagir.

No excerto 19, a professora conclui sua autoavaliação e utiliza-se do verbo "estar". Embora não tenha se colocado como "professora contratada", ou seja, não aceita a categorização imposta pela proposta da ficha de autoavaliação, a expressão "estar aqui" pode indicar que a professora tem clareza da temporalidade definida do contrato, e ela a demarca, mas deixando claro que - assim como as demais - aprecia a permanência.

Essa apreciação positiva é evidenciada pela categoria avaliação. Todas as orações da professora refletem algum dos tipos de avaliação, coerentes com texto em que se deve avaliar a própria atuação e apresentar dificuldades. Na primeira e segunda orações (16), realiza avaliações deodônticas; a primeira indica, por meio da modalidade advérbio "sempre" -, grau de comprometimento com sua obrigação.

Recordemos que a categoria avaliação refere-se ao significado identificacional. Resende e Ramalho destacam, de Fairclough, a importância do estudo da modalidade:

[...] a modalidade é entendida como a relação entre o(a) autor(a) de um texto e a representação. A modalidade é relevante na construção discursiva de identidades, porque "o quanto você se compromete é uma parte significativa do que você é - então escolhas de modalidades em textos sempre podem ser vistas como parte do processo de texturização de identidades (Fairclough, 2003a, p. 166)". ${ }^{16}$ (RESENDE; RAMALHO, 2006, p. 75)

A modalidade e a avaliação deodôntica reforçam a autoapresentação da professora como profissional que reflete sobre sua prática, comprometida com o trabalho, alunos e seu aprendizado.

Em seguida, a professora apresenta duas avaliações na forma de presunções valorativas, conforme excertos 17 e 18. No excerto 17, destacamos as escolhas "já", "uma", "bastante", "no meio" e "depois de uma greve", que permitem a leitura de avaliação negativa do contexto da entrada em sala por parte da docente. Já no excerto 19, a mencionada preferência por "amenizada", além de "apoio e orientação", "recepção" e "compreensão", permite apreender que, contraposto ao que foi negativo - a dificuldade -, a professora identifica pontos positivos, inclusive pela sua percepção, registro da ação de pais (compreensão) e forma pela qual foi recebida pelos alunos (recepção).

Ao final, segue uma afirmação avaliativa: “(20) Destaco toda organização e entusiasmo dos profissionais do Colégio X como essenciais para aquilo que eu buscava encontrar: experiências no fazer da rede pública que estão distanciadas do fracasso escolar". 
A professora explicita a atuação de outros profissionais na escola e que essa ação é importante para a consecução de algo que deseja encontrar. Ao final, faz avaliação afetiva (19): “estar aqui é a materialização [...]".

Quanto à categoria identificação relacional, também produtora de significado identificacional, Maria parece desejar explicitar as boas relações sociais construídas com os membros da comunidade escolar: os alunos a receberam (bem), os pais compreenderam o momento difícil da entrada, e as equipes (não especificadas) a auxiliaram a amenizar quaisquer dificuldades que ela, professora com iniciativa, responsabilidade e foco nas "necessidades dos alunos", possa ter apresentado. Aliás, o excerto 16 indica a professora se definir enquanto docente também por característica apontada por Tardif e Lessard:

[...] compreendida como uma forma particular de trabalho sobre o humano, ou seja, uma atividade em que o trabalhador se dedica ao "objeto" de seu trabalho, que é justamente outro ser humano, no modo fundamental da interação humana. Podemos chamar de interativo esse trabalho sobre e com outrem. (TARDIF; LESSARD, 2005, p. 8-9)

Maria busca, discursivamente, mostrar-se a seus avaliadores uma boa docente por estar atenta às necessidades de seus alunos, motivá-los e buscar o que desperte seus interesses. Essa foi uma estratégia discursiva diferente da professora Gabriela, que não trouxe a "voz" dos alunos, e também da professora Ana, para quem a função dos alunos não fica tão explícita (eles "vieram no momento certo").

Sobre a análise do Texto 3, poderíamos resumir dizendo que a professora Maria busca se construir discursivamente como alguém que sabe o que faz (ensinar), com quem faz (equipes, pais, alunos) e por que e para que faz (o que deseja alcançar com os alunos e para a sociedade). Além disso, tem autoridade para apontar problemas institucionais e a autonomia esperada de profissional docente que - apesar de ciente de sua transitoriedade (“estar aqui") - não deixa de se expor e manifestar opiniões, tentando equilibrar a balança do poder de forma mais autoral e simétrica.

\section{CONSIDERAC̣ÕES FINAIS SOBRE AS ANÁLISES}

O presente artigo buscou lançar luz sobre o trabalho exercido por professoras temporariamente contratadas em instituições federais brasileiras a partir de ângulo peculiar: o discursivo. Debruçar-se sobre o discurso dessas docentes, os modos como eles representam a si mesmas e a sua atividade, em interações sociais específicas, ajuda 
a iluminar as formas pelas quais duas categorias docentes, efetivos e contratados, são muitas vezes construídas de modo assimétrico e problemático para os projetos institucionais.

As três professoras que compuseram a amostra de dados apresentam-se em um contínuo que vai desde autorrepresentações passivas e subalternizadas em relação a outros profissionais da escola até aquelas que, infelizmente em minoria no corpus, reivindicam para si identidades agentivas e que, mesmo diante das delicadezas da tarefa autoavaliativa, têm voz para dizer sobre sua prática e a escola de forma mais horizontalizada e menos idealizada.

Ainda que se faça ressalva, notam-se as formas como diferentes textos construídos apresentam certas recorrências. Todas as docentes-participantes procuram apresentar o Colégio X como instituição que consegue realizar educação pública "de qualidade". Tal "qualidade" é naturalmente polemizada entre os diferentes textos. Ora se associa ao "renome" da instituição, como visto na análise do Texto 1, ora representa "experiências no fazer da rede pública que estão distanciadas do fracasso escolar", como no Texto 3. De qualquer forma, o elogio à escola vem acompanhado de desejo de permanência justificado pelo tanto que se "aprende" com a instituição.

Os efeitos de sentido dessa equação discursiva podem ser vistos a partir de dois pontos de vista complementares. De um lado, o desejo de continuar "aprendendo" com o colégio indexicaliza um apartamento de si em relação à instituição. O desejo de permanência, em poucas palavras, pressupõe não pertença. Não pertencer, isto é, não resistir às relações subalternizadas, em contexto político pautado pela nova gestão pública, em que o número de contratados por vezes ultrapassa vinte por cento do corpo docente, para além do problema óbvio da naturalização das relações de poder, significa operar em instituição cindida, possibilitando a falta de coesão e horizontalidade entre seus profissionais.

Por outro lado, nota-se também que a experiência do contrato é representada como positiva e importante pelas participantes da pesquisa. Logo, do ponto de vista de suas trajetórias individuais, há um ganho na interação delas com a instituição que não pode ser ignorado. Tardif e Lessard defendem que a construção da identidade docente, atualmente, cabe mais ao próprio professor do que a um processo de transmissão institucional, como outrora (TARDIF; LESSARD, 2005, p. 50-51). Além disso, os autores afirmam que a identidade docente tem um componente de flexibilidade:

[...] sua identidade é menos definida por seu papel codificado do que por suas relações humanas cotidianas com seus alunos e colegas de trabalho; sua situação 
tem menos a ver com o organograma da organização do que com as negociações diárias com outros agentes educativos. (TARDIF; LESSARD, 2005, p. 45)

Poderíamos, a partir disso, pensar que a relação com instituição representada como comprometida, organizada, competente, etc., talvez tenha apresentado às docentes nova forma de ser professor e de atuar em equipe, como identidade de projeto (RESENDE; RAMALHO, 2006, p. 78). Não seria exagero supor que, ao vivenciarem novas possibilidades de ser, estar, fazer e representar, essas docentes possam modificar outros espaços de atuação e suas próprias identidades.

\section{REFERÊNCIAS}

BAKHTIN, M. Estética da criação verbal. Tradução de Maria Ermantina Galvão. Revisão da tradução de Marina Appenzeller. 3. ed. São Paulo: Martins Fontes, 2000.

BALL, S. J. Diretrizes políticas globais e relações públicas locais em Educação. Currículo sem Fronteiras, [S.1.], v. 1, n. 2, p. 99-106, jul./dez. 2001.

BRASIL. Presidência da República. Câmara da Reforma do Estado. Plano Diretor da Reforma do Aparelho do Estado. Brasília, 1995. Disponível em: <http://www. bresserpereira.org.br/Documents/MARE/PlanoDiretor/planodiretor.pdf $>$. Acesso em: 8 maio 2014.

FAIRCLOUGH, N. Análise Crítica do Discurso como método em Pesquisa Social Científica. Linha d'Água, São Paulo, v. 25, n. 2, p. 307-329, 2012.

FARIA, G. S. S. Organização do trabalho do professor: jornada, contrato e conflitos trabalho-família. 2010. 173 f. Tese (Doutorado em Gestão da Produção Industrial) - Centro de Ciências Exatas e de Tecnologia, Universidade Federal de São Carlos, São Carlos, 2010.

GOFFMAN, E. Estigma: notas sobre a manipulação da identidade deteriorada. Rio de Janeiro: Guanabara, 1988.

MANCEBO, D. Agenda de pesquisa e opções teórico-metodológicas nas investigações sobre trabalho docente. Educação e Sociedade, Campinas, v. 28, n. 99, p. 466-482, maio/ago. 2007. Disponível em: <http://www.scielo.br/pdf/es/v28n99/a09v2899.pdf>. Acesso em: 27 maio 2014.

RESENDE, V. de M.; RAMALHO, V. C. Análise do discurso crítica. São Paulo: Contexto, 2006. RESENDE, V. de M.; RAMALHO, V. C. Análise de Discurso (para a) Crítica: o texto como material de pesquisa. Campinas: Pontes Editores, 2011. (Coleção Linguagem e Sociedade, v. 1)

SCHULZ, T W. Investment in Human Capital. American Economic Review, Pittsburgh, v. 51, n. 1, p. 1-17, mar. 1961.

TARDIF, M.; LESSARD, C. O trabalho docente: elemento para uma teoria da docência como profissão de interação humana. 2. ed. Petrópolis: Vozes, 2005.

THOMPSON, J. Ideologia e cultura moderna. Petrópolis: Vozes, 1995.

\section{NOTAS}

${ }^{1}$ Todos os nomes são fictícios para atender aos parâmetros éticos da pesquisa. 
${ }^{2}$ BHASKAR, R. Scientific realism and human emancipation. London: Verso, 1986.

${ }^{3}$ BHASKAR, R. Scientific realism and human emancipation. London: Verso, 1986.

${ }^{4}$ OECD. Governance in Transition: Public Management Reforms in OECD Countries. Paris: Organisation for Economic Co-operation and Development, 1995.

${ }^{5}$ MANCEBO, D.; FRANCO, M. E. D. P. Trabalho docente: uma análise das práticas intelectuais em tempos de globalização. In: DOURADO, L. F.; CATANI, A. M.; OLIVEIRA, J. F. (Orgs.). Politicas e gestão da educação superior: transformações recentes e debates atuais. São Paulo: Xamã; Goiânia: Alternativa, 2003. p. 191-204.

${ }^{6} \mathrm{~A}$ adjetivação está presente na proposta.

${ }^{7}$ CHOULIARAKI, L.; FAIRCLOUGH, N. Discourse in Late Modernity: Rethinking critical discourse analysis. Edinbourgh: Edinbourgh University Press, 1999.

${ }^{8}$ FAIRCLOUGH, N. Analysing Discourse: textual analysis for social research. London: Routledge, 2003.

${ }^{9}$ Os nomes das professoras também são fictícios.

${ }^{10}$ Para fins de referência na análise explanatória, os excertos estarão numerados como esse, entre parênteses.

${ }^{11}$ HALLIDAY, M. A. K. Introduction to Functional Grammar. London: Hodder Arnold, 2004.

${ }^{12}$ RESENDE, V. M. Análise de discurso crítica e realismo crítico. Implicações interdisciplinares. Campinas: Pontes Editores, 2009.

${ }^{13}$ Reforçamos que as autoavaliações aqui transcritas não sofreram alterações em relação ao modo como foram redigidas pelas professoras participantes da pesquisa.

${ }^{14}$ Setor de Supervisão e Orientação Pedagógica (SESOP).

${ }^{15}$ CASTELLS, M. O poder da identidade. São Paulo: Paz e Terra, 1999.

${ }^{16}$ FAIRCLOUGH, N. Analysing Discourse: textual analysis for social research. London: Routledge, 2003.

Submetido: $19 / 07 / 2016$

Aprovado: 11/10/2016

Contato:

Colégio Pedro II - Campus São Cristóvão I

Campo de São Cristóvão, 177. São Cristóvão

Rio de Janeiro $|\mathrm{RJ}|$ Brasil

CEP 20.921-440 